\title{
NeuroBlate System
}

National Cancer Institute

\section{Source}

National Cancer Institute. NeuroBlate System. NCI Thesaurus. Code C157734.

A proprietary, minimally invasive robotic laser thermotherapy tool, designed specifically for use in the brain, that uses MRI-guided surgical ablation technology. It is designed to provide precise and maximal tumor reduction without the invasiveness of an open neurosurgical procedure. 